\title{
Simultaneous degradation of two mycotoxins enabled by a fusion enzyme in food-grade recombinant Kluyveromyces lactis
}

\author{
Yu Xia ${ }^{1,2,3^{*}} \oplus$, Zifeng $\mathrm{Wu}^{1,2}$, Rui He ${ }^{1,2}$, Yahui Gao ${ }^{1,2}$, Yangyu Qiu ${ }^{1,2}$, Qianqian Cheng ${ }^{1,2}$, Xiaoyuan $\mathrm{Ma}^{1,2,3}$ and \\ Zhouping Wang ${ }^{1,2,3}$
}

\begin{abstract}
Aflatoxin $\mathrm{B}_{1}\left(\mathrm{AFB}_{1}\right)$ and zearalenone (ZEN) are two predominant mycotoxins ubiquitously found in corn, peanuts, and other grains, which pose a great threat to human health. Therefore, safe and effective methods for detoxification of these mycotoxins are urgently needed. To achieve simultaneous degradation of multiple mycotoxins, a fusion enzyme ZPF1 was constructed by linking zearalenone hydrolase and manganese peroxidase with a linker peptide GGGGS. This fusion enzyme was secretory expressed successfully in the newly constructed food-grade recombinant strain Kluyveromyces lactis GG799(pKLAC1-ZPF1), and was investigated with the mycotoxins degradation efficiency in two reaction systems. Results showed that both $\mathrm{AFB}_{1}$ and ZEN can be degraded by ZPF1 in reaction system 1 (70.0 mmol/L malonic buffer with $1.0 \mathrm{mmol} / \mathrm{L} \mathrm{MnSO}_{4}, 0.1 \mathrm{mmol} / \mathrm{L} \mathrm{H}_{2} \mathrm{O}_{2}, 5.0 \mu \mathrm{g} / \mathrm{mL} \mathrm{AFB}$ and ZEN, respectively) with the ratios of $46.46 \%$ and $38.76 \%$, respectively. In reaction system $2(50.0 \mathrm{mmol} / \mathrm{L}$ Tris $-\mathrm{HCl}$, with $5.0 \mu \mathrm{g} / \mathrm{mL} \mathrm{AFB}$ and ZEN, respectively), AFB 1 cannot be degraded while ZEN can be degraded with the ratio of $35.38 \%$. To improve the degradation efficiency of these mycotoxins, optimization of the induction and degradation conditions were fulfilled subsequently. The degradation ratios of $\mathrm{AFB}_{1}$ and ZEN by ZPF1 in reaction system 1 reached $64.11 \% \pm 2.93 \%$ and $46.21 \% \pm 3.17 \%$, respectively. While in reaction system 2, ZEN was degraded by ZPF1 at a ratio of $41.45 \% \pm 3.34 \%$. The increases of degradation ratios for $\mathrm{AFB}_{1}$ and ZEN in reaction system 1 were $17.65 \%$ and $7.45 \%$, respectively, while that for ZEN in reaction system 2 was 6.07\%, compared with the unoptimized results.
\end{abstract}

Keywords: Mycotoxins, Aflatoxin $B_{1}$, Zearalenone, Fusion enzyme, Degradation, Kluyveromyces lactis, Food-grade

\section{Introduction}

Among the mycotoxins that have been widely researched, aflatoxins (AFs) are the most toxic and pose the greatest threat to human health. Among all the AFs analogs, aflatoxin $\mathrm{B}_{1}\left(\mathrm{AFB}_{1}\right)$ possesses the strongest toxicity and usually causes severe harm to human beings and animals. For example, $\mathrm{AFB}_{1}$ is clearly associated to liver carcinogenesis, neurotoxicity, and growth retardation (Nazhand et al. 2020). Zearalenone

\footnotetext{
*Correspondence: yuxia@jiangnan.edu.cn

${ }^{1}$ State Key Laboratory of Food Science and Technology, Jiangnan

University, Wuxi 214122, China

Full list of author information is available at the end of the article
}

(ZEN) is another kind of mycotoxins mainly caused by Fusarium, which is commonly found in corn and rice in high temperature or warm climate regions (Lee and Ryu 2017). ZEN contains estrogen-active isophthalic acid lactone, which can bind to and activate estrogen receptors, and disrupts the reproductive and endocrine systems. In general, most of the contaminated foods contains more than one kind of mycotoxins, and the interaction of multiple mycotoxins may cause more lethal damage (Lee and Ryu 2017; Alassane-Kpembi et al. 2017). With the presence of $\mathrm{ZEN}, \mathrm{AFB}_{1}$ has a synergistic effect on cytotoxicity in a concentrationdependent manner. Low-level contaminated $\mathrm{AFB}_{1}$ can 
antagonize $\mathrm{ZEN}$, but high-dose $\mathrm{AFB}_{1}$ and $\mathrm{ZEN}$ show a synergistic effect on oxidative damage (Lei et al. 2013).

Because of the harmful effects of mycotoxins to human health, efficient detoxification methods are urgently needed worldwide (Haque et al. 2020). For detoxification and degradation of mycotoxins, several kinds of strategies can be employed, such as physical, chemical, and biological methods (Nazhand et al. 2020; Liu et al. 2020; Wan et al. 2020; Wu et al. 2020; Zhou et al. 2020). Among these methods, biological detoxification is considered as the safer, gentler, and more effective choice for degradation of mycotoxins into less toxic intermediates or non-toxic products (Adebo et al. 2015; Wang et al. 2019a). It has been reported that a wide range of microorganisms including bacteria and fungi can decrease the toxicity of mycotoxins by cell wall adsorptions or intracellular metabolic processes (Armando et al. 2012; Brana et al. 2017; Gonzalez Pereyra et al. 2020; Zhang et al. 2021). Recently, the works of enrichment, purification, genetic engineering, and heterologous expression of many specific toxindegrading enzymes are increasingly playing important roles in mycotoxins degradations (Loi et al. 2020; Wang et al. 2019b; Zhang et al. 2020). Considering the diversity of multiple mycotoxins contaminated in foods, a single specific mycotoxin-degrading enzyme can no longer meet the future needs. Although some probiotics, enzymes, and strains can be combined together to achieve simultaneous degradation of multiple mycotoxins, these methods are cumbersome, inefficient and not suitable for industrial applications (Afshar et al. 2020; Wang 2017; Yin 2018). Therefore, multifunctional enzymes that can simultaneously detoxify a wide range of mycotoxins are urgently needed.

Fusion protein technology is now widely used in field of protein engineering. Yet fusion enzymes for simultaneous degradation of multiple mycotoxins were seldom reported (Azam et al. 2019). Construction of fusion proteins involved in the linking of different proteins or domains by peptide linkers (Arai et al. 2001; Chen et al. 2013; Crasto and Feng 2000). Recently, the hydrolase ZHD101 and carboxypeptidase had been fused together with a connecting peptide containing five amino acids, and the fusion enzyme was successfully expressed in Escherichia coli with dual functions of degrading zearalenone (ZEN) and ochratoxin A (OTA) (Azam et al. 2019), which might be the first report of fusion protein used for mycotoxins degradation. However, E. coli is a type of opportunistic pathogen and is sometimes unsuitable for expression of fungal-derived enzymes, especially those enzymes used in food industry. In contrast, the food-grade yeast expression host Kluyveromyces lactis is the preferred one for expression of varieties of enzymes which involved in food processing (Lachance 2007; Pacheco et al. 2012; Wang et al. 2016).

In this work, a fusion enzyme of zearalenone hydrolase and manganese peroxidase for the simultaneous degradation of $\mathrm{AFB}_{1}$ and $\mathrm{ZEN}$ was designed, constructed and expressed in a food-grade manner. The zearalenone hydrolase ZHD101.1 (ZHD101 mutant V153H) from Clonostachys rosea (Xu et al. 2016; Xu 2019; Zhou 2017) and manganese peroxidase PhcMnp from Phanerochaete chrysosporium (Sun 2020; Jarvinen et al. 2012; Stewart et al. 1996; Coconi-Linares et al. 2014) were selected for construction of fusion enzymes, with (GGGGS) $(n=1 \sim 4)$ as the linker peptides. These two individual enzymes had ever been, respectively, expressed in $E$. coli (Hui et al. 2017; Whitwam et al. 1995) and yeasts (Gu et al. 2003; Xu 2019; Wang et al. 2020;). This fusion enzyme was successfully secretory expressed in the foodgrade host $K$. lactis GG799. The degradation efficiency for $A_{F B}$ and $Z E N$ by the fusion enzyme were evaluated, and the induction conditions, as well as the degradation conditions, were also optimized in this work.

\section{Materials and methods Chemicals and reaction systems}

$\mathrm{AFB}_{1}$ and $\mathrm{ZEN}$ were purchased from Pribolab (Shandong, China). In this research work, these standards were made into a $1.0 \mathrm{mg} / \mathrm{mL}$ stock solution with methanol or acetonitrile solvent, and were preserved with refrigeration in darkness at $-20{ }^{\circ} \mathrm{C}$. Restriction enzymes, T4 DNA ligase, and plasmid extraction kits were purchased from Thermo Fisher Scientific (Shanghai, China). Hemin and sorbitol were purchased from Aladdin (Shanghai, China). Protein markers, protein loading buffers, SDS gel stain washing buffers, fungus genomic DNA extraction kits were purchased from Sangon Biotech (Shanghai, China). Methanol, formic acid, and acetonitrile were purchased from Tedia (OH, USA). All other reagents and chemicals were of analytical reagent grade.

Two reaction systems were used for mycotoxins degradation in this work. The reaction system 1 contained $70.0 \mathrm{mmol} / \mathrm{L}$ malonic acid buffer with $1.0 \mathrm{mmol} / \mathrm{L}$ $\mathrm{MnSO}_{4}, 0.1 \mathrm{mmol} / \mathrm{L} \mathrm{H}_{2} \mathrm{O}_{2}, 5.0 \mu \mathrm{g} / \mathrm{mL} \mathrm{AFB}_{1}$ and $5.0 \mu \mathrm{g} /$ $\mathrm{mL}$ ZEN (Wang et al. 2019b). The reaction system 2 contained $50.0 \mathrm{mmol} / \mathrm{L}$ Tris- $\mathrm{HCl}(\mathrm{pH} 7.5)$ with $5.0 \mu \mathrm{g} / \mathrm{mL}$ $\mathrm{AFB}_{1}$ and $5.0 \mu \mathrm{g} / \mathrm{mL} \mathrm{ZEN}$ (Xiang et al. 2016).

\section{Plasmids, strains, cultural conditions and DNA manipulations}

The coding genes for the enzymes ZHD101.1 and PhcMnp were previously synthesized and cloned into DH $5 \alpha($ pKLAC1-zhd101.1) and DH5 $\alpha$ (pKLAC1-Phcmnp) by GenScript (Nanjing, China) and preserved in this laboratory. The expression hosts K. lactis GG799, E. coli 
DH5 $\alpha$ and the secretory expression vector pKLAC1 were preserved in this laboratory. The plasmids pKLAC1ZPF1, pKLAC1-ZPF2, pKLAC1-ZPF3, pKLAC1-ZPF4, and recombinant strain $K$. lactis GG799(pKLAC1-ZPF1) were constructed in this work.

Growth media components were purchased from Oxoid (Thermo Fisher Scientific, Shanghai). For cultivation of $K$. lactis GG799, the strain was grown in YEPD medium (yeast extract $1 \%$, peptone $2 \%$, glucose $2 \%, \mathrm{pH}$ 6.3) at $30{ }^{\circ} \mathrm{C}, 200 \mathrm{rpm}$ for 18 to $22 \mathrm{~h}$. For induction expression of ZPF1, YEPG medium (1.0\% yeast extract, $2.0 \%$ peptone, $2.0 \%$ galactose, $0.5 \mathrm{mmol} / \mathrm{L} \mathrm{MnSO}_{4}, 0.5 \mathrm{mmol} / \mathrm{L}$ hemin, $\mathrm{pH}$ 5.9) was used and the strain was cultivated at $30{ }^{\circ} \mathrm{C}, 200 \mathrm{rpm}$ for $96 \mathrm{~h}$. The genome DNA of K. lactis recombinants were extracted and purified by fungus genomic DNA extraction kit. All the DNA sequencing works were done in Sangon Biotech (Shanghai, China).

\section{Construction of fusion genes and recombinant plasmids}

Plasmids in two strains DH5 $\alpha$ (pKLAC1-zhd101.1) and DH $5 \alpha$ (pKLAC1-Phcmnp) were extracted as templates. The primers (zhd101.1-F, zhd101.1-R) and (PhcmnpF, Phcmnp-R) were used for PCR amplification of the two genes. The two PCR results were purified, respectively. These PCR results were mixed as templates, and the primers $z h d 101.1-\mathrm{Fn}$ and Phcmnp-Rn $(n=1 \sim 4)$ were used for the overlapping PCR to obtain the fusion genes. The fusion genes obtained were then cloned in the expression vector pKLAC1 to generate recombinant plasmids pKLAC1-ZPFn. The recombinant plasmids from the positive clones were purified, verified by DNA sequencing and then transformed $K$. lactis GG799. The GG799 transformants were verified by PCR using the primers pKLAC1-seq-F and pKLAC1-seq-R. All the primers used for plasmids construction and verification are listed in Additional file 1: Table S1. Detailed procedures for construction of the plasmids and the recombinant strains are shown in Fig. 1.

\section{Expression of fusion enzyme ZPF1 in recombinant $K$. lactis GG799(pKLAC1-ZPF1)}

The recombinants of $K$. lactis GG799(pKLAC1-ZPF1) were cultivated in the YEPD medium at $30{ }^{\circ} \mathrm{C}$ for about 18 to $22 \mathrm{~h}$ at a speed of $200 \mathrm{rpm}$. When the $\mathrm{OD}_{600}$ of the cultures reached 1.0, the cells were transferred into YEPG induction medium and cultivated at $30{ }^{\circ} \mathrm{C}, 200 \mathrm{rpm}$ for $96 \mathrm{~h}$ for expression of the fusion enzymes. The supernatants of these cultures were collected by centrifugation, and the protein samples were concentrated with 10.0$\mathrm{kDa}$ ultrafiltration tubes. The concentrated solution samples containing the enzyme were used for subsequent biochemical analysis. Proteins were quantified with BCA protein quantitative kit, and then analyzed and identified by SDS-PAGE (20.0 $\mu \mathrm{g}$ proteins per lane).

\section{Degradation of $\mathrm{AFB}_{1}$ and ZEN by ZPF1}

Since the two domains (ZHD101.1 and PhcMnp) on the fusion enzyme ZPF1 had different reaction requirements

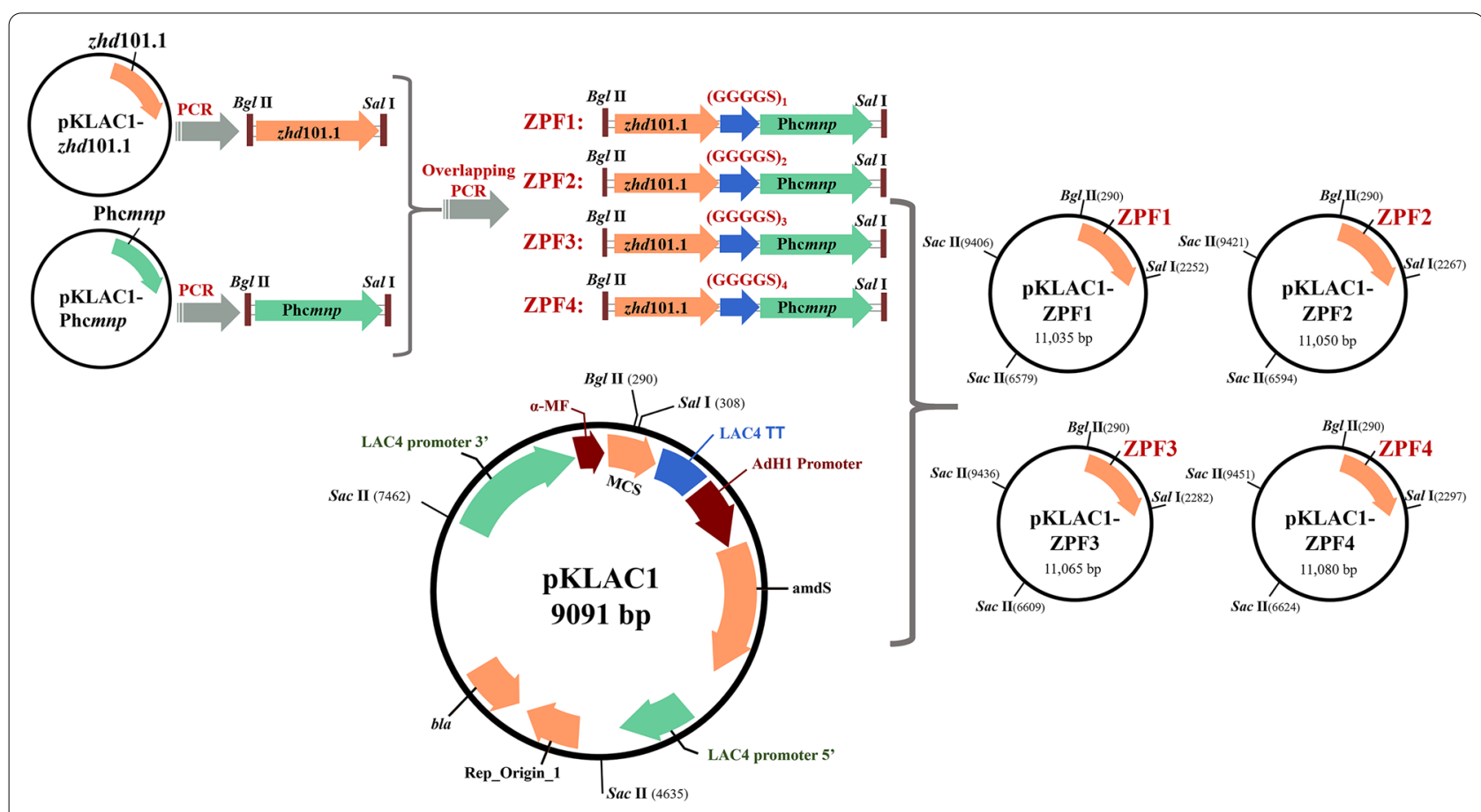

Fig. 1 Flowchart for construction of fusion genes and recombinant plasmids 
for degradation of the two mycotoxins, two different reaction systems were required to verify the $A F B_{1}$ and ZEN degradation efficiency by ZPF1. The reaction system 1 and 2 mentioned above were employed for this purpose. For degradation of the two mycotoxins in reaction system 1, the solution containing all the samples needed was incubated at $30{ }^{\circ} \mathrm{C}$ for $9 \mathrm{~h}$, followed by adding $3.0 \mathrm{~mL}$ methanol for termination of the reaction (Wang et al. 2019b). For degradation of the two mycotoxins in reaction system 2 , the solution containing all the samples needed was incubated at $37{ }^{\circ} \mathrm{C}$ for $30 \mathrm{~min}$, followed by adding $1.0 \mathrm{~mL}$ methanol for termination of the reaction (Xiang et al. 2016).

In the figures, the degradation ratios of ZEN in the reaction systems 1 and 2 were denoted as ZEN-1 and ZEN-2, respectively. The $\mathrm{AFB}_{1}$ and ZEN standards were prepared with the concentration gradients $(0.1 \mu \mathrm{g} / \mathrm{mL}$, $0.2 \mu \mathrm{g} / \mathrm{mL}, 0.5 \mu \mathrm{g} / \mathrm{mL}, 1.0 \mu \mathrm{g} / \mathrm{mL}, 2.0 \mu \mathrm{g} / \mathrm{mL}, 5.0 \mu \mathrm{g} / \mathrm{mL}$, in acetonitrile) for determination of the standard curves. As controls of degradation reactions, the $\mathrm{AFB}_{1}$ and $\mathrm{ZEN}$ were prepared in buffers at the final concentration of $5.0 \mu \mathrm{g} / \mathrm{mL}$, respectively. All the experiments were performed in triplicate.

\section{Quantitative analysis of $\mathrm{AFB}_{1}$ and ZEN}

The reaction mixture was filtered through a $0.22-\mu \mathrm{m}$ filter and the remaining contents of $\mathrm{AFB}_{1}$ and $\mathrm{ZEN}$ were analyzed by UPLC-MS (Sun 2020). The UPLC-MS running parameters were as following: chromatographic was done using ACQUITY UPLC ${ }^{\circledR}$ BEH C18 $(2.1 \times 50 \mathrm{~mm}$, $1.7 \mu \mathrm{m}$ particle size); the mobile phase was acetonitrile/ water/formic acid; flow rate was $0.3 \mathrm{~mL} / \mathrm{min}$; column temperature was $40{ }^{\circ} \mathrm{C}$. Mass spectrometry parameters were as following: electrospray ion source; multiple reaction monitoring modes (MRM); cone Voltage was $3.0 \mathrm{kV}$; heating gas temperature was $500{ }^{\circ} \mathrm{C}$; ion source temperature was $150{ }^{\circ} \mathrm{C}$; desolventizing gas rate was $800.0 \mathrm{~L} / \mathrm{h}$.

\section{Enzyme activity assay}

The fusion enzyme ZPF1 contained two enzyme domains (ZHD101.1 and PhcMnp). The enzyme activity of PhcMnp was determined by the phenol red method (Wang et al. 2014) as following: $10.0 \mathrm{mmol} / \mathrm{L}$ $\mathrm{MnSO}_{4}, 100.0 \mathrm{mmol} / \mathrm{L}$ sodium malonate buffer $(\mathrm{pH}$ 4.5), $0.25 \mathrm{mmol} / \mathrm{L}$ phenol red and $1.0 \mathrm{~mL}$ crude enzyme. The absorbance of the reaction mixture was measured at $624 \mathrm{~nm}$. The reaction was initiated by adding $100.0 \mathrm{mmol} / \mathrm{L} \mathrm{H}_{2} \mathrm{O}_{2}$ and reacted for $5 \mathrm{~min}$ at $30{ }^{\circ} \mathrm{C}$. Then the reaction was immediately terminated by adding $1 \%$ $\mathrm{NaOH}$ to the system. The changes of absorbance before and after the reaction were calculated for determination of enzyme activities. One unit of enzyme activity (U) was defined as following: The quantity of enzyme PhcMnp needed for oxidation of $1.0 \mathrm{mmol}$ of the substrate in $1 \mathrm{~min}$. The enzyme activity of zearalenone hydrolase was characterized by the degradation ratio of ZEN (Zhang et al. 2020).

\section{Optimization of ZPF1 induction conditions}

According to the previous researches, the promoter LAC4 in plasmid pKLAC1 was induced by galactose and inhibited by glucose (Xu 2019). The recombinant strain K. lactis GG799(pKLAC1-ZPF1) was cultivated with different induction conditions (induction time: 24 to $144 \mathrm{~h}$, induction temperature: $15{ }^{\circ} \mathrm{C}$ to $35{ }^{\circ} \mathrm{C}$, concentration of galactose: 5.0 to $80.0 \mathrm{~g} / \mathrm{L}$, concentration of $\mathrm{MnSO}_{4}$ : 0.1 to $5.0 \mathrm{mmol} / \mathrm{L}$, and concentration of hemin: 0.05 to $2.0 \mathrm{mmol} / \mathrm{L}$ ), and the enzymes were secretory expressed into the supernatants (Gnanamani et al. 2006). The expression levels of ZPF1 were single-factor optimized and characterized by specific enzyme activities $\left(\mathrm{AFB}_{1}\right)$ or degradation ratios (ZEN).

\section{Optimization of mycotoxins degradation conditions}

The $\mathrm{AFB}_{1}$ and ZEN degradation efficiency were optimized, respectively by testing of the degradation ratios at different reaction conditions. For optimization of $\mathrm{AFB}_{1}$ and ZEN degradation in reaction system 1 , the reaction time $(0.5$ to $10 \mathrm{~h})$, temperature $\left(20{ }^{\circ} \mathrm{C}\right.$ to $\left.70{ }^{\circ} \mathrm{C}\right)$, protein concentration $(0.1$ to $5.0 \mathrm{mg} / \mathrm{mL}), \mathrm{pH}$ (3.0 to 5.5$)$, concentration of $\mathrm{MnSO}_{4}(0.1$ to $5.0 \mathrm{mmol} / \mathrm{L})$, concentration of $\mathrm{H}_{2} \mathrm{O}_{2}(0.1$ to $5.0 \mathrm{mmol} / \mathrm{L})$ were investigated separately. For optimization of ZEN degradation in reaction system 2 , the reaction time (10 to $180 \mathrm{~min})$, temperature $\left(20{ }^{\circ} \mathrm{C}\right.$ to $\left.70{ }^{\circ} \mathrm{C}\right)$, protein concentration $(0.1$ to $5.0 \mathrm{mg} / \mathrm{mL}), \mathrm{pH}$ (6.0 to 8.5 ) were also investigated separately. The detailed reaction procedures were performed according to the methods described above.

\section{Results and discussion \\ Construction, expression and degradation of $\mathrm{AFB}_{1}$ and $\mathrm{ZEN}$ by ZPF 1}

To obtain recombinant fusion enzyme that can degrade $\mathrm{AFB}_{1}$ and ZEN simultaneously, four fusion plasmids were constructed in this work according to the methods described above. The flowchart for the construction is shown in Fig. 1. The recombinant plasmids were transferred K. lactis GG799 host, and the transformants were selected and verified by PCR amplifications. In these transformants, 3 positive transformants from the pKLAC1-ZPF1 transformation plates were successfully obtained. Other transformants from pKLAC1-ZPF2 to pKLAC1-ZPF4 transformation plates were all PCR negative. The PCR results of pKLAC1-ZPF1 transformants are shown in Fig. 2a. The lengths of the result bands were all around 2500 bp (Fig. 2a, Lane L1 to L3), which were 

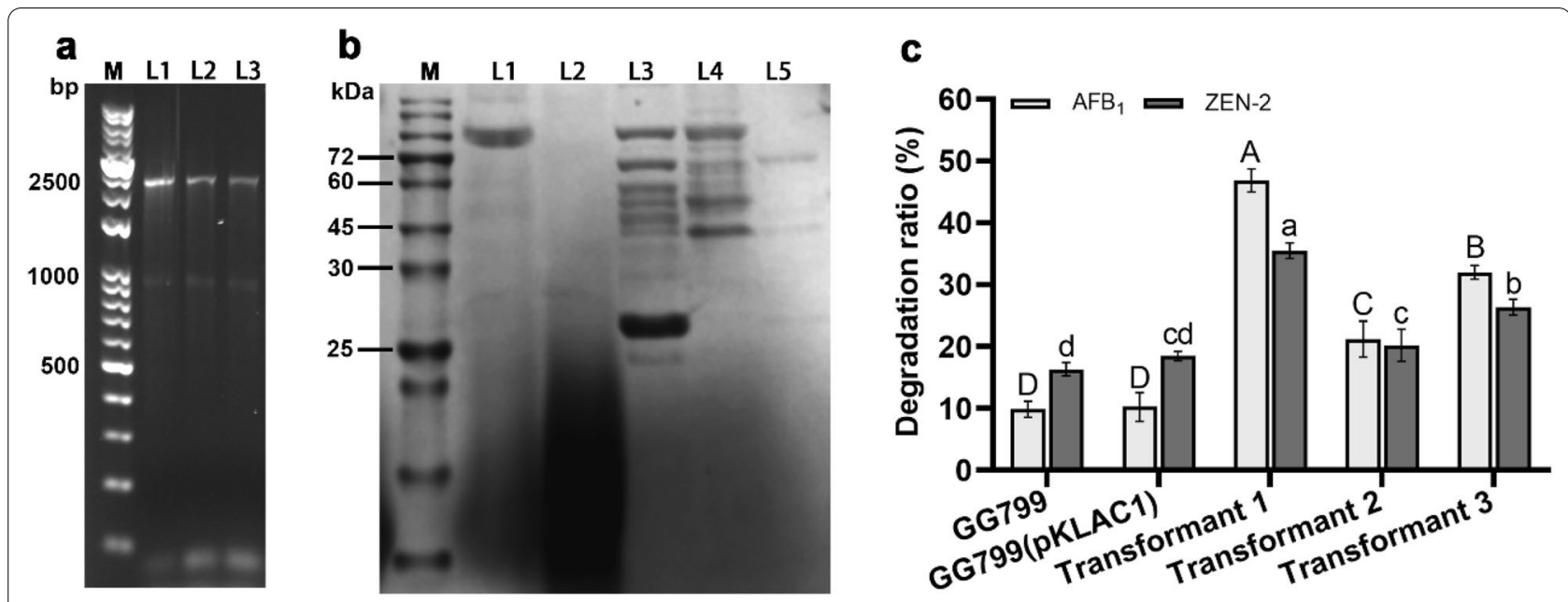

Fig. 2 Construction and expression of fusion enzyme ZPF1, and the degradation efficiency of AFB 1 and ZEN by ZFP1. a The electrophoresis of the PCR results of the 3 positive transformants: M: DNA marker; L1 to L3: PCR results of 3 positive GG799(pKLAC1-ZPF1) transformants. $\mathbf{b}$ SDS-PAGE results of culture supernatants of the 3 positive transformants: M: Protein marker; L1: K. lactis GG799 supernatant proteins; L2: K. lactis GG799(pKLAC1) supernatant proteins; L3 to L5: Three K. lactis GG799(pKLAC1-ZPF1) transformants' supernatant protein. c Degradation results of $A_{F B}$ (reaction system 1) and ZEN (reaction system 2) by the 3 transformants. Different letters above the histogram are significant differences $(p<0.05)$

near the theoretical size of the heterologous insertion. The PCR results were sequenced for determination of the successful constructions.

The 3 recombinant $K$. lactis GG799(pKLAC1-ZPF1) strains were induced and the enzymes were secretory expressed. As shown in the lane L3 in Fig. 2b, the expressed ZPF1 enzymes had the molecular weight of about $70.0 \mathrm{kDa}$ on SDS-PAGE, which was close to its theoretical molecular weight of $69.23 \mathrm{kDa}$, while the controls (Fig. 2b, Lanes L1 and L2) showed no band around the target size. In comparison, the target protein in Lane L3 indicated the highest expression level among the 3 samples (Lanes L3 to L5). Besides, a protein band with the molecular weight above $25.0 \mathrm{kDa}$ is found in Lane L3 in Fig. 2b. In consideration that the enzyme ZHD101.1 had the molecular weight of $28.8 \mathrm{KDa}$, this band might be the fractured domain of ZHD101.1 from the ZPF1.

The enzyme activities of PhcMnp and ZHD101.1 in the ZPF1 were determined according to the methods described above. The transformants 1,2 and 3 showed the PhcMnp activities with the specific form of $3.18 \mathrm{U} /$ $\mathrm{mg}, 0.94 \mathrm{U} / \mathrm{mg}$, and $1.85 \mathrm{U} / \mathrm{mg}$, respectively, while the enzyme activities of ZHD101.1 (characterized by ZEN degradation ratio) were $35.38 \%, 20.23 \%$ and $26.34 \%$, respectively. As shown in Fig. 2c, the mycotoxins degradation efficiency using ZPF1 expressed by the 3 different transformants were investigated. Results showed that the enzyme from the transformant 1 had the best reaction activities to both $\mathrm{AFB}_{1}$ (in reaction system 1) and ZEN (in reaction system 2), with the degradation ratios of $46.46 \%$ and $35.38 \%$, respectively (Fig. 2c). In contrast, the two negative controls, K. lactis GG799 and K. lactis GG799(pKLAC1) showed a small degradation efficiency of $\mathrm{AFB}_{1}$ and $\mathrm{ZEN}$ (about $10 \%$ and $17 \%$, respectively). In conclusion, the transformant 1 showed the best performance in enzyme activity and degradation efficiency, and it was selected out for the further optimization.

\section{Optimization of induction expression conditions for ZPF1}

Enzyme expression, such as the expression of zearalenone hydrolase (Xu 2019), is usually influenced by several factors like incubation times, temperatures, and nitrogen source levels. In this system, the transcription and expression of the target enzyme were influenced by the concentration of galactose added. Besides, the PhcMnp activity of the ZPF1 was additional regulated by $\mathrm{Mn}^{2+}$ and hemin levels, during the induction expression procedure (Whitwam and Tien 1996; Gnanamani et al. 2006). Therefore, all these factors were investigated in this work, according to the methods described. As shown in Fig. 3, the trends of enzyme activities of PhcMnp and ZHD101.1 in ZPF1 under different induction conditions were approximately similar. With the increase of induction time (Fig. 3a), temperature (Fig. 3b), galactose (Fig. 3c), $\mathrm{MnSO}_{4}$ (Fig. 3d), and hemin (Fig. 3e) concentrations, the enzyme activities of both enzymes showed the trends of increasing and then decreasing.

It can be seen from Fig. 3c, a high concentration of galactose inhibited the fusion enzyme activity. This conclusion was similar to that from the previous research 


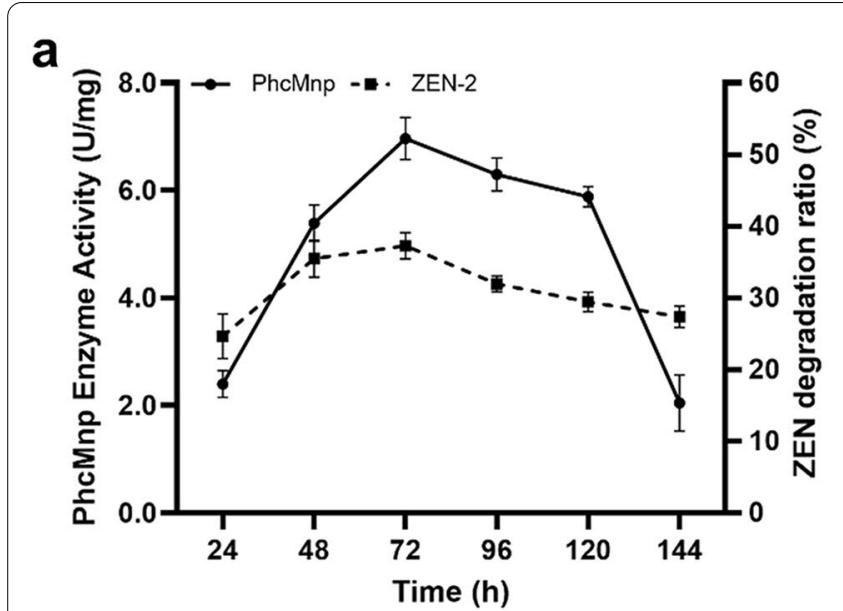

b

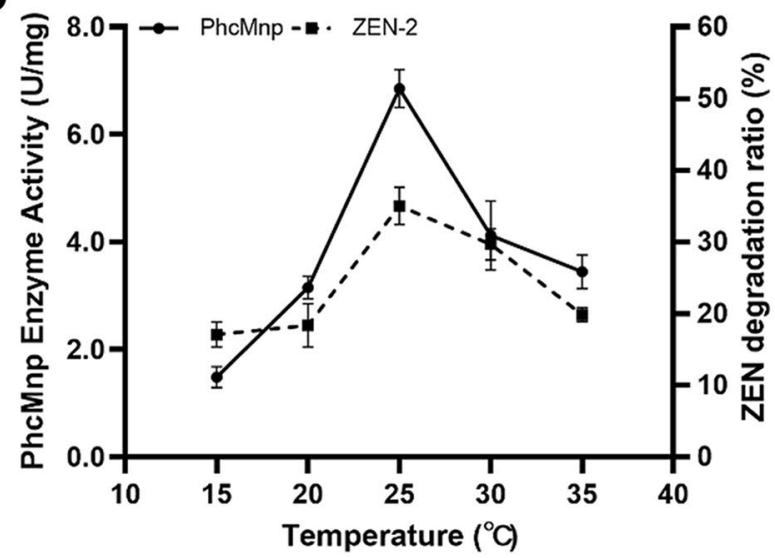

C

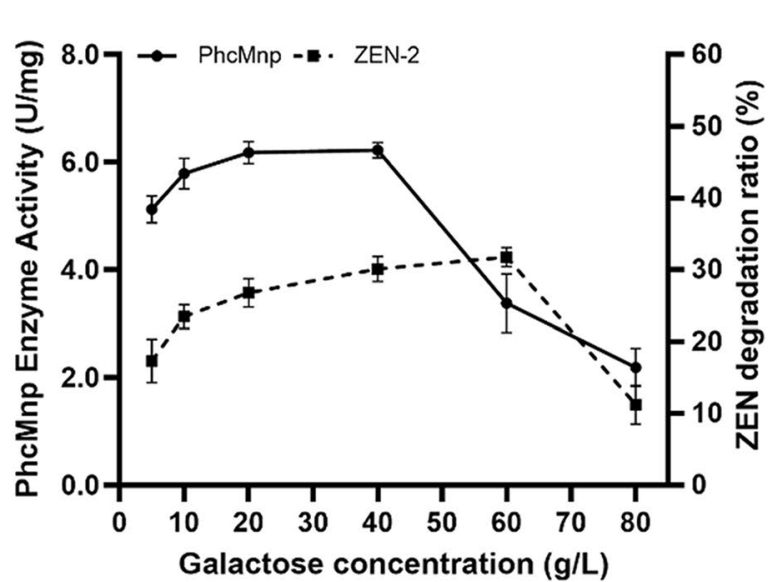

d

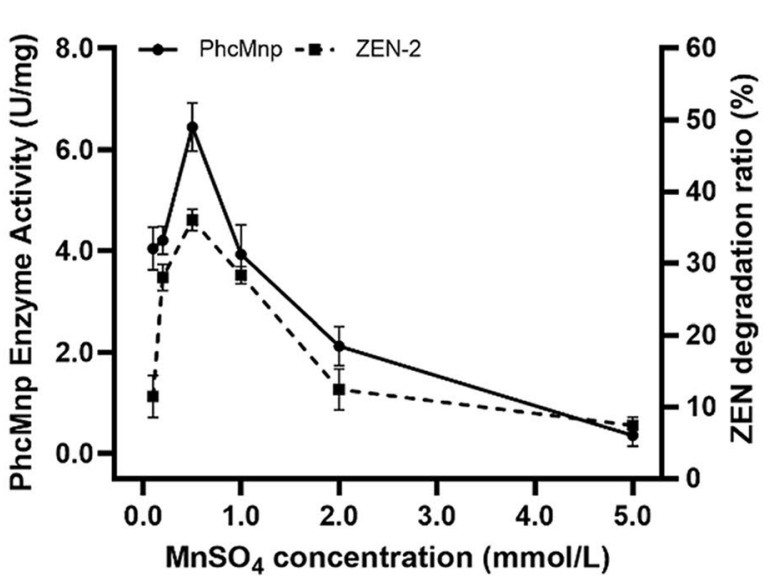

e

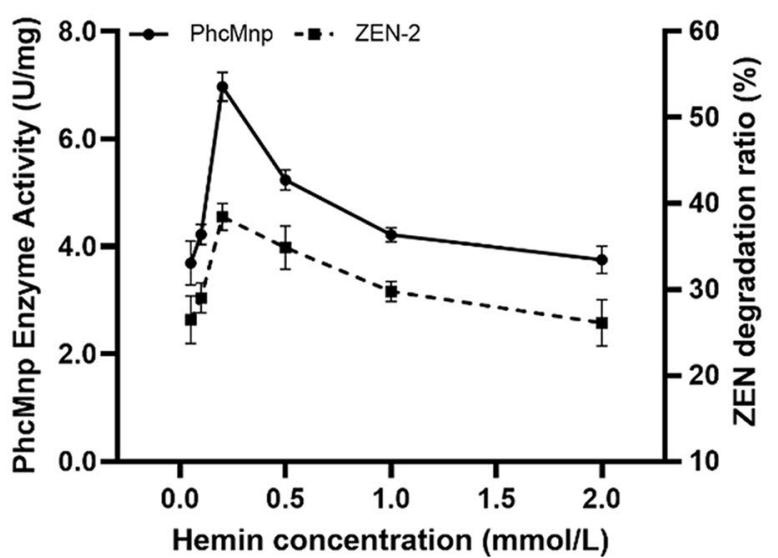

Fig. 3 Enzyme activity of PhcMnp and ZHD101.1 expressed by ZPF1 under different induction conditions. The left axes were the PhcMnp enzyme activities, and the right axes were the degradation ratios of ZEN (by ZHD101.1). a-e were the effects of time, temperature, galactose concentrations, $\mathrm{MnSO}_{4}$ concentrations and hemin concentrations on the enzyme activities of the ZPF1

results. The galactose as an inducer added to the culture in low concentrations could not completely initiate heterologous protein expression, while high concentrations of it inhibited the protein expression, which might because of the carbon-to-nitrogen ratio $(\mathrm{C} / \mathrm{N})$ was not suitable any more (Xu 2019; Sun 2020). 
As shown in Fig. 3d, the enzymatic activity gradually decreased as the $\mathrm{Mn}^{2+}$ concentration increased. When the concentration of $\mathrm{Mn}^{2+}$ was $0.5 \mathrm{mmol} / \mathrm{L}$, the PhcMnp activity of the ZPF1 reached the highest value of $6.44 \mathrm{U} /$ mg. With the increased concentration of $\mathrm{Mn}^{2+}$ added in the induction system, the PhcMnp activity decreased drastically. It was reported that enzyme PhcMnp was regulated by $\mathrm{Mn}^{2+}$ at the transcriptional level, and a certain amount of $\mathrm{Mn}^{2+}$ may promote the synthesis of PhcMnp (Wang 2014; Whitwam and Tien 1996). However, when the concentration of $\mathrm{Mn}^{2+}$ was too high, it inhibited the enzyme expression (Tang et al. 2012).

Furthermore, since PhcMnp is a glycosylated peroxidase containing heme iron (heme-Fe), which is essentially a highly helical pentameric protein containing $\mathrm{Fe}^{3+}$, additional appropriate amounts of hemin adding in the induction medium can provide $\mathrm{Fe}^{3+}$ for effectively initiation of enzyme synthesis (Jiang et al. 2008; Wang et al. 2016; Whitwam et al. 1995; Mayfield et al. 1994). However, similar to the influence of $\mathrm{Mn}^{2+}$ to the enzyme activity, high concentrations of hemin also inhibit PhcMnp enzyme activity (Fig. 3e), which is consistent with the findings of the previous reports (Jiang et al. 2008; Sun 2020).

Unlike the special requirements for expression of PhcMnp, the expression of ZHD101.1 was theoretically not affected by $\mathrm{Mn}^{2+}$ and hemin. However, high concentrations of $\mathrm{Mn}^{2+}$ also affects the enzyme expression by inhibiting the growth of yeast cells (Tang et al. 2012), so the enzyme activities of ZHD101.1 also showed decreasing trends with the increasing concentrations of $\mathrm{Mn}^{2+}$ added (Fig. 3d, e).

From the results shown above, it can be found that the optimized conditions for induction expression of ZPF1 were: inducing at $25{ }^{\circ} \mathrm{C}$ for $72 \mathrm{~h}$, in YEPG medium containing $40.0 \mathrm{~g} / \mathrm{L}$ galactose, $0.5 \mathrm{mmol} / \mathrm{L} \mathrm{MnSO}_{4}$ and $0.2 \mathrm{mmol} / \mathrm{L}$ hemin.

\section{Optimization of degradation reaction conditions for $A_{F} B_{1}$ and ZEN}

In this work, there were two systems for the degradation reaction of $\mathrm{AFB}_{1}$ and $\mathrm{ZEN}$. The reaction system 1 contained $\mathrm{MnSO}_{4}$ and $\mathrm{H}_{2} \mathrm{O}_{2}$ and was used for degradation of $\mathrm{AFB}_{1}$ by PhcMnp, while the reaction system 2 was used for degradation of ZEN by ZHD101.1, as described in the methods above. Here the degradation conditions were optimized, respectively, in these two reaction systems.

In reaction system 1 , the conditions such as times, temperatures. protein concentrations and $\mathrm{pH}$ were investigated, respectively, and the results are shown in Fig. $4 \mathrm{a}-\mathrm{d}$. In this reaction system, the $\mathrm{Mn}^{2+}$ and $\mathrm{H}_{2} \mathrm{O}_{2}$ were critical elements for catalytic reactions. With the participation of a suitable concentration of $\mathrm{H}_{2} \mathrm{O}_{2}$, the $\mathrm{Mn}^{2+}$ was oxidized to $\mathrm{Mn}^{3+}$ by PhcMnp, and then the high redox potential of $\mathrm{Mn}^{3+}$ catalyzed and transferred the substrates to low toxic or non-toxic compounds (Whitwam and Tien 1996).

However, as shown in Fig. 4e, high concentrations of $\mathrm{Mn}^{2+}$ inhibited the degradation ratios of both $\mathrm{AFB}_{1}$ and ZEN. When the $\mathrm{MnSO}_{4}$ concentration was $0.2 \mathrm{mmol} / \mathrm{L}$, the degradation ratios of $\mathrm{AFB}_{1}$ and $\mathrm{ZEN}$ were $47.36 \%$ and $46.01 \%$, respectively. At the $\mathrm{MnSO}_{4}$ concentration of $5.0 \mathrm{mmol} / \mathrm{L}$, the degradation ratios of $\mathrm{AFB}_{1}$ and $\mathrm{ZEN}$ were decreased to $10.35 \%$ and $11.6 \%$. Furthermore, the degradation efficiency of mycotoxins was also affected by the concentration of $\mathrm{H}_{2} \mathrm{O}_{2}$ in reaction system 1 . According to the previous reports, peroxidases could be inactivated through their own suicide inactivation mechanism with presence of high concentration of $\mathrm{H}_{2} \mathrm{O}_{2}$ (Valderrama et al. 2002; Zhang 2010). As shown in Fig. 4f, the degradation ratios of $A F B_{1}$ and $Z E N$ reached the maximum values $(44.2 \%$ and $41.87 \%)$ at the $\mathrm{H}_{2} \mathrm{O}_{2}$ concentration of $1.0 \mathrm{mmol} / \mathrm{L}$, while those at the $\mathrm{H}_{2} \mathrm{O}_{2}$ concentration of $5.0 \mathrm{mmol} / \mathrm{L}$ were $7.0 \%$ and $5.3 \%$, respectively.

In conclusion, the optimal conditions for degradation of both mycotoxins by the ZPF1 in reaction system 1 were: malonic acid buffer ( $\mathrm{pH} 4.0$ ) containing $0.2 \mathrm{mmol} / \mathrm{L}$ $\mathrm{MnSO}_{4}$ and $1.0 \mathrm{mmol} / \mathrm{L} \mathrm{H}_{2} \mathrm{O}_{2}$, added with $2.0 \mathrm{mg} / \mathrm{mL}$ expressed proteins, reacted at $40{ }^{\circ} \mathrm{C}$ for $8 \mathrm{~h}$. Under optimized conditions, the degradation ratios of $\mathrm{AFB}_{1}$ and ZEN both reached the maximum data of $64.11 \% \pm 2.93 \%$ and $46.21 \% \pm 3.17 \%$, respectively.

As for degradation of $\mathrm{ZEN}$, most of the reported reaction systems for zearalenone hydrolases were Tris- $\mathrm{HCl}$ buffers (pH 7.5) (Xu 2019; Xiang et al. 2016), and this reaction system was used here as the reaction system 2 in this work. As shown by the results in Additional file 1: Figure $\mathrm{S} 3, \mathrm{AFB}_{1}$ cannot be degraded in this system, so here the optimal conditions were investigated for degradation of ZEN.

The degradation ratio for ZEN by ZPF1 reached 39.01\% after 30-min reaction in reaction system 2 (Fig. 5a). In comparison, with the same reaction time (30 $\mathrm{min})$, the degradation ratio of ZEN by ZPF1 in reaction system 1 was only $13.63 \%$ (Fig. 4a). This result suggested that reaction system 2 was better for degradation of ZEN. However, with the increase of reaction time, the degradation ratio of $\mathrm{ZEN}$ in reaction system 1 reached $41.58 \%$ after $10 \mathrm{~h}$ of reaction (Fig. 4a). Considering the time cost in actual processing, the reaction system 2 might be the favorable one for degradation of ZEN.

As shown in Fig. 5, the optimal conditions for reaction system 2 were: Tris-HCl buffer ( $\mathrm{pH} 7.5)$, added with $2.0 \mathrm{mg} / \mathrm{mL}$ expressed proteins, reacted at $40{ }^{\circ} \mathrm{C}$ for $30 \mathrm{~min}$. In compared with the previous studied (Xu 2019), the degradation ratio for ZEN in this work was 


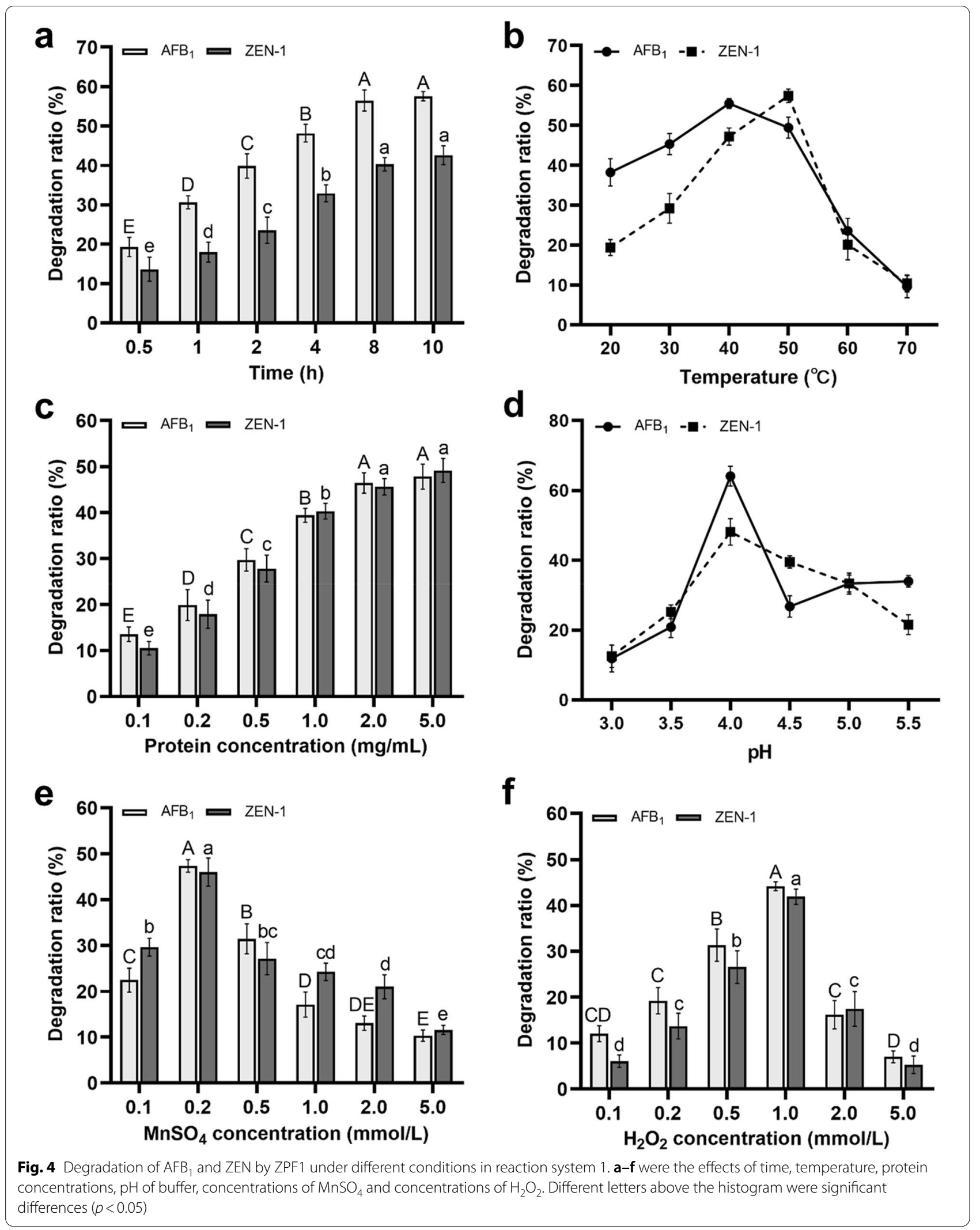




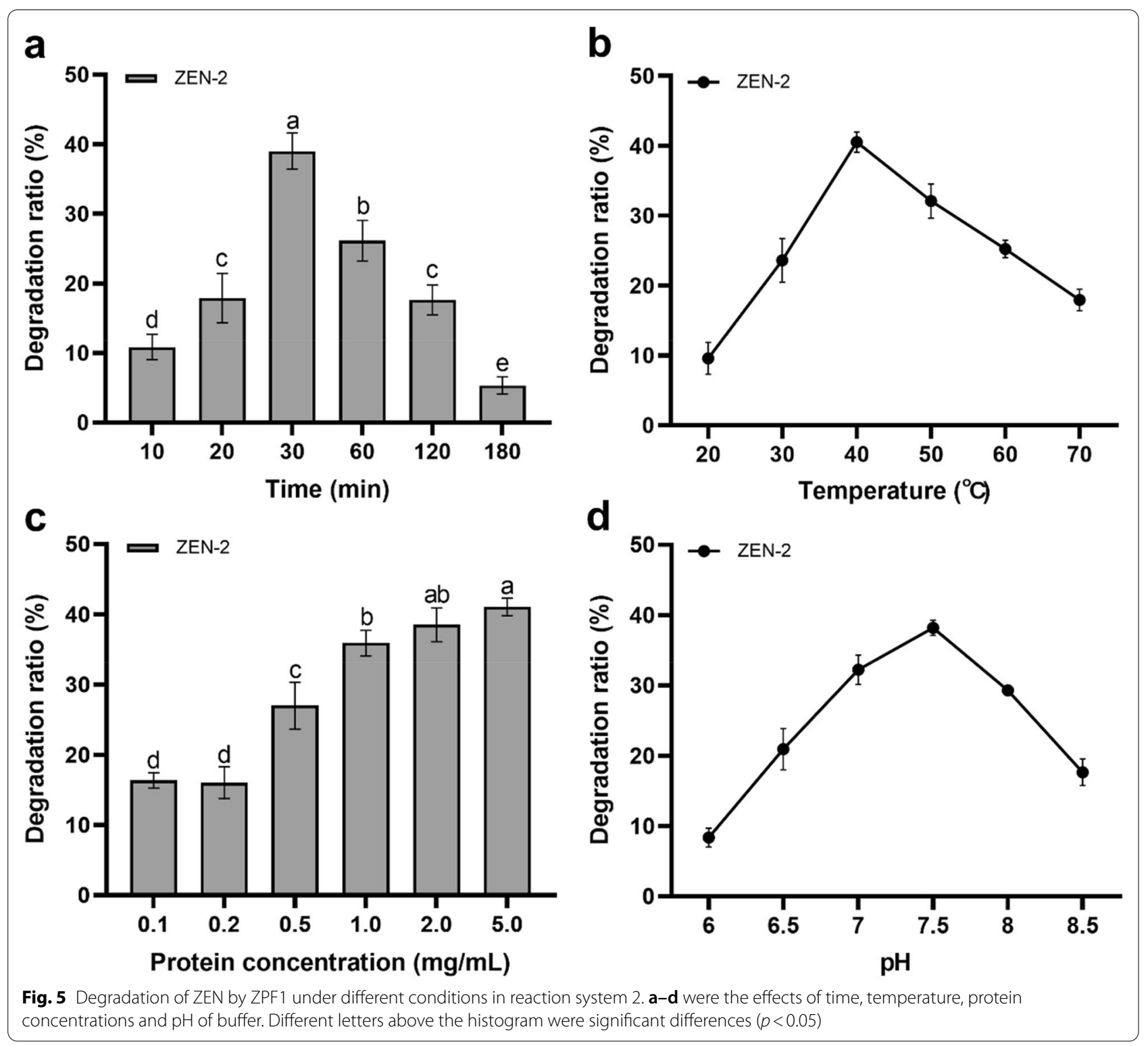

obviously lower than the results of $\mathrm{Xu}$. The reason for this phenomenon might because of the usage of flexible peptide GGGGS as the linker in the fusion enzyme. As reported previously, usage of the flexible linkers in fusion enzymes might cause dimers of the side-by-side protein domains, and such a conformation obscured the active sites of the fusion enzyme and leading to a decrease in enzyme activity (Chen et al. 2013; Li et al. 2015). In future researches, other types of peptide linkers, such as rigid linkers $(\text { EAAAK })_{n}$, could be tested for elimination of the possible mutual interference of two functional protein domains.

Furthermore, the degradation efficiency of the two mycotoxins in these two systems were still not so good, compared with results of separately studied enzymatic degradation efficiency (Xu 2019; Sun 2020). Reaction systems that are suitable for both enzymes ZHD101.1 and PhcMnp could be further studied in the future.

\section{Conclusions}

Mycotoxins detoxification and degradation are worldwide problems. Although various means had been applied for enhancing degradation efficiency of mycotoxins, there are few reports on fusion enzymes for simultaneous degradation of multiple toxins. For simultaneous degradation of $\mathrm{AFB}_{1}$ and $\mathrm{ZEN}$, a fusion enzyme with the functions of zearalenone hydrolase (ZHD101.1) and manganese peroxidase (PhcMnp) was constructed 
and secretory expressed successfully in this work. The enzymes used for construction of the fusion one were both originated from food safe microorganisms. Meanwhile, the food-grade expression kits, i.e. the host $K$. lactis GG799 and the vector pKLAC1, were used in this work. So the secretory expression of the fusion enzyme ZPF1 was achieved in a food-grade manner. Therefore, this enzyme has the possibility of practical applications in food industry in the future.

\begin{abstract}
Abbreviations
$\mathrm{AFB}_{1}$ : Aflatoxin $\mathrm{B}_{1}$; ZEN: Zearalenone; OTA: Ochratoxin $\mathrm{A} ;$ K. lactis: Kluyveromyces lactis; E. coll: Escherichia coll; ZEN-1: Degradation ratio of ZEN by the fusion enzyme ZPF1 in reaction system 1; ZEN-2: degradation ratio of ZEN by the fusion enzyme ZPF1 in reaction system 2; UPLC-MS: Ultra-performance liquid chromatography/tandem mass spectrometry; PCR: Polymerase chain reaction; SDS-PAGE: Sodium dodecyl sulfate polyacrylamide gel electrophoresis; ZPF1: The fusion enzyme constructed by fusing the individual enzymes ZHD101.1 and PhcMnp using the linking peptide GGGGS.
\end{abstract}

\section{Supplementary Information}

The online version contains supplementary material available at https://doi. org/10.1186/s40643-021-00395-1.

Additional file 1: Table S1. Primers used in this study for PCR. Figure S1. Liquid chromatography of the degradation results of $\mathrm{AFB}_{1}$ by the fusion enzyme ZPF1 in reaction system 1. Figure $\mathbf{S 2}$. Liquid chromatography of the degradation results of ZEN by the fusion enzyme ZPF1 in reaction system 1. Figure S3. Liquid chromatography of the degradation results of $A F B_{1}$ by the fusion enzyme ZPF1 in reaction system 2. Figure S4. Liquid chromatography of the degradation results of ZEN by the fusion enzyme ZPF1 in reaction system 2.

\section{Acknowledgements}

This work was supported by Jiangsu Agriculture Science and Technology Innovation Fund (JASTIF) with the No.: CX(19)3109, and Key Research and Development Program of Jiangsu Province (BE2018306).

\section{Authors' contributions}

$Y X$ conceived the research strategies, designed the experiments, gave important guidance to the experiments, and assisted in completing the final manuscript. ZW designed the experiments, conducted the experiments, prepared the manuscript. $\mathrm{RH}, \mathrm{YG}, \mathrm{YQ}$ and $\mathrm{QC}$ provided some investigations and experimental technique supports. XM and ZW provided experience guidance and partial financial supports for the experiments. All authors read and approved the final manuscript.

\section{Funding}

Jiangsu Agriculture Science and Technology Innovation Fund (JASTIF) with the No.: CX(19)3109. Key Research and Development Program of Jiangsu Province (BE2018306). Jiangsu Overseas Research \& Training Program for University Prominent Young \& Middle-aged Teachers and Presidents

\section{Availability of data and materials}

All data generated or analyzed during this study are included in this article.

\section{Declarations}

Ethics approval and consent to participate

Not applicable.

\section{Consent for publication}

All authors agreed with this publication.

\section{Competing interests}

The authors declare that they have no competing interests.

\section{Author details}

${ }^{1}$ State Key Laboratory of Food Science and Technology, Jiangnan University, Wuxi 214122, China. ${ }^{2}$ School of Food Science and Technology, Jiangnan University, Wuxi 214122, China. ${ }^{3}$ Collaborative Innovation Center of Food Safety and Quality Control in Jiangsu Province, Jiangnan University, Wuxi 214122, China.

Received: 5 April 2021 Accepted: 11 May 2021

Published online: 15 July 2021

\section{References}

Adebo OA, Njobeh PB, Gbashi S, Nwinyi OC, Mavumengwana V (2015) Review on microbial degradation of aflatoxins. Food Sci Nutr 57(15):3208-3217. https://doi.org/10.1080/10408398.2015.1106440

Afshar P, Shokrzadeh M, Raeisi SN, Ghorbani-HasanSaraei A, Nasiraii LR (2020) Aflatoxins biodetoxification strategies based on probiotic bacteria. Toxicon 178:50-58. https://doi.org/10.1016/j.toxicon.2020.02.007

Alassane-Kpembi I, Schatzmayr G, Taranu I, Marin D, Puel O, Oswald IP (2017) Mycotoxins co-contamination: Methodological aspects and biological relevance of combined toxicity studies. Crit Rev Food Sci Nutr 57(16):3489-3507. https://doi.org/10.1080/10408398.2016.1140632

Arai R, Ueda H, Kitayama A, Kamiya N, Nagamune T (2001) Design of the linkers which effectively separate domains of a bifunctional fusion protein. Protein Eng 14(8):529-532. https://doi.org/10.1093/protein/14.8.529

Armando MR, Pizzolitto RP, Dogi CA, Cristofolini A, Merkis C, Poloni V, Dalcero AM, Cavaglieri LR (2012) Adsorption of ochratoxin A and zearalenone by potential probiotic Saccharomyces cerevisiae strains and its relation with cell wall thickness. J Appl Microbiol 113:256-264. https://doi.org/10. 1111/j.1365-2672.2012.05331.x

Azam MS, Yu D, Liu N, Wu A (2019) Degrading ochratoxin A and zearalenone mycotoxins using a multifunctional recombinant enzyme. Toxins. https:// doi.org/10.3390/toxins11050301

Brana MT, Cimmarusti MT, Haidukowski M, Logrieco AF, Altomare C (2017) Bioremediation of aflatoxin B1-contaminated maize by king oyster mushroom (Pleurotus eryngii). PLoS ONE. https://doi.org/10.1371/journal. pone.0182574

Chen X, Zaro JL, Shen WC (2013) Fusion protein linkers: property, design and functionality. Adv Drug Deliv Rev 65(10):1357-1369. https://doi.org/10. 1016/j.addr.2012.09.039

Coconi-Linares N, Magana-Ortiz D, Guzman-Ortiz DA, Fernandez F, Loske AM, Gomez-Lim MA (2014) High-yield production of manganese peroxidase, lignin peroxidase, and versatile peroxidase in Phanerochaete chrysosporium. Appl Microbiol Biotechnol 98(22):9283-9294. https://doi.org/ 10.1007/s00253-014-6105-9

Crasto CJ, Feng JA (2000) LINKER: a program to generate linker sequences for fusion proteins. Protein Eng 13(5):309-312. https://doi.org/10.1093/prote in/13.5.309

Gnanamani A, Jayaprakashvel M, Arulmani M, Sadulla S (2006) Effect of inducers and culturing processes on laccase synthesis in Phanerochaete chrysosporium NCIM 1197 and the constitutive expression of laccase isozymes. Enzyme Microb Technol 38(7):1017-1021. https://doi.org/10. 1016/j.enzmictec.2006.01.004

Gonzalez Pereyra ML, Di Giacomo AL, Lara AL, Martinez MP, Cavaglieri L (2020) Aflatoxin-degrading Bacillus sp. strains degrade zearalenone and produce proteases, amylases and cellulases of agro-industrial interest. Toxicon 180:43-48. https://doi.org/10.1016/j.toxicon.2020.04.006

Gu L, Lajoie C, Kelly C (2003) Expression of a Phanerochaete chrysosporium manganese peroxidase gene in the yeast Pichia pastoris. Biotechnol Prog 19:1403-1409. https://doi.org/10.1021/bp025781h

Haque MA, Wang Y, Shen Z, Li X, Saleemi MK, He C (2020) Mycotoxin contamination and control strategy in human, domestic animal and poultry: A review. Microb Pathog. https://doi.org/10.1016/j.micpath.2020.104095

Hui R, Hu X, Liu W, Liu W, Zheng Y, Chen Y, Guo RT, Jin J, Chen CC (2017) Characterization and crystal structure of a novel zearalenone hydrolase from Cladophialophora bantiana. Acta Crystallogr F Struct Biol Commun 73:515-519. https://doi.org/10.1107/S2053230X17011840 
Jarvinen J, Taskila S, Isomaki R, Ojamo H (2012) Screening of white-rot fungi manganese peroxidases: a comparison between the specific activities of the enzyme from different native producers. AMB Express 2:62. https:// doi.org/10.1186/2191-0855-2-62

Jiang F, Kongsaeree P, Charron R, Lajoie C, Xu H, Scott G, Kelly C (2008) Production and separation of manganese peroxidase from heme amended yeast cultures. Biotechnol Bioeng 99(3):540-549. https://doi.org/10.1002/ bit. 21590

Lachance MA (2007) Current status of Kluyveromyces systematics. FEMS Yeast Res 7(5):642-645. https://doi.org/10.1111/j.1567-1364.2006.00197.x

Lee HJ, Ryu D (2017) Worldwide occurrence of mycotoxins in cereals and cereal-derived food products: Public health perspectives of their cooccurrence. Food Chem 65(33):7034-7051. https://doi.org/10.1021/acs. jafc.6b04847

Lei M, Zhang N, Qi D (2013) In vitro investigation of individual and combined cytotoxic effects of aflatoxin B1 and other selected mycotoxins on the cell line porcine kidney 15. Exp Toxicol Pathol 65:1149-1157. https://doi org/10.1016/j.etp.2013.05.007

Li J, Wang C, Wu M (2015) Design of connecting peptide and its application in fusion protein. J Food Sci Biotechnol 34(11):1121-1127. https://doi.org/ 10.3969/j.issn.1673-1689.2015.11.001

Liu Y, Galani Yamdeu JH, Gong YY, Orfila C (2020) A review of postharvest approaches to reduce fungal and mycotoxin contamination of foods. Compr Rev Food Sci Food Safety. https://doi.org/10.1111/1541-4337. 12562

Loi M, Renaud JB, Rosini E, Pollegioni L, Vignali E, Haidukowski M, Sumarah MW, Logrieco AF, Mule G (2020) Enzymatic transformation of aflatoxin B by Rh_DypB peroxidase and characterization of the reaction products. Chemosphere. https://doi.org/10.1016/j.chemosphere.2020.126296

Mayfield MB, Kishi K, Alic M, Gold MH (1994) Homologous expression of recombinant manganese peroxidase in Phanerochaete chrysosporium. Appl Environ Microbiol 60(12):4303-4309. https://doi.org/10.1128/AEM. 60.12.4303-4309.1994

Nazhand A, Durazzo A, Lucarini M, Souto EB, Santini A (2020) Characteristics, occurrence, detection and detoxification of aflatoxins in foods and feeds. Foods. https://doi.org/10.3390/foods9050644

Pacheco B, Crombet L, Loppnau P, Cossar D (2012) A screening strategy for heterologous protein expression in Escherichia coli with the highest return of investment. Protein Expr Purif 81(1):33-41. https://doi.org/10. 1016/j.pep.2011.08.030

Stewart P, Whitwam RE, Kersten PJ, Cullen D, Tien M (1996) Efficient expression of a Phanerochaete chrysosporium manganese peroxidase gene in Aspergillus oryzae. Appl Environ Microbiol 62(3):860-864. https://doi.org/ 10.1128/Aem.62.3.860-864.1996

Sun Y (2020) Study on expression of manganese peroxidase and its degradation of aflatoxin by recombinant yeast. Dissertation, Jiangnan University.

Tang Y, Yue L, Peng C, Song Y, Tan H (2012) The effect of growth and phenol degrading on phenol degrading strain $\mathrm{XH}-10$ with different metal ions. Bioprocess 2(1):31-39. https://doi.org/10.12677/bp.2012.21006

Valderrama B, Ayala M, Vazquez-Duhalt R (2002) Suicide inactivation of peroxidases and the challenge of engineering more robust enzymes. Chem Biol 9(5):555-565. https://doi.org/10.1016/s1074-5521(02)00149-7

Wan J, Chen B, Rao J (2020) Occurrence and preventive strategies to control mycotoxins in cereal-based food. Compr Rev Food Sci Food Safety 19(3):928-953. https://doi.org/10.1111/1541-4337.12546

Wang J (2014) Study on manganese peroxidase gene expression in Pichia pastoris and lignin degradation in corn straw. Dissertation, Henan Agricultural University.

Wang L (2017) Preparation of composite enzyme preparation for efficient degradation of aflatoxin B 1 . China Patent 106636017 A, May 2017.
Wang N, Ren K, Jia R, Chen W, Sun R (2016) Expression of a fungal manganese peroxidase in Escherichia coli: a comparison between the soluble and refolded enzymes. BMC Biotechnol 16(1):87. https://doi.org/10.1186/ s12896-016-0317-2

Wang N, Wu W, Pan J, Long M (2019a) Detoxification strategies for zearalenone using microorganisms: A review. Microorganisms. https://doi.org/10. 3390/microorganisms7070208

Wang X, Qin X, Hao Z, Luo H, Yao B, Su X (2019b) Degradation of four major mycotoxins by eight manganese peroxidases in presence of a dicarboxylic acid. Toxins. https://doi.org/10.3390/toxins11100566

Wang Y, Wang Y, Jiang J, Zhao Y, Xing F, Zhou L (2020) [High expression of zearalenone degrading enzyme in Pichia pastoris. Chin J Biotechnol 36(2):372-380. https://doi.org/10.13345/j.cjb.190150

Whitwam R, Tien M (1996) Heterologous expression and reconstitution of fungal Mn peroxidase. Arch Biochem Biophys 333(2):439-446. https://doi. org/10.1006/abbi.1996.0413

Whitwam RE, Gazarian IG, Tien M (1995) Expression of fungal Mn peroxidase in E. coli and refolding to yield active enzyme. Biochem Biophys Res Commun 216(3):1013-1017. https://doi.org/10.1006/bbrc.1995.2721

Wu S, Wang F, Li Q, Wang J, Zhou Y, Duan N, Niazi S, Wang Z (2020) Photocatalysis and degradation products identification of deoxynivalenol in wheat using upconversion nanoparticles@TiO $\mathrm{Ti}_{2}$ composite. Food Chem. https:// doi.org/10.1016/j.foodchem.2020.126823

Xiang WQ, Zhou Y, Yin L, Zhang G, Ma Y (2016) High-level expression of a ZENdetoxifying gene by codon optimization and biobrick in Pichia pastoris. Microbiol Res 193:48-56. https://doi.org/10.1016/j.micres.2016.09.004

Xu R (2019) Mutational modification, secretion expression and application of zearalenone degrading enzyme Zhd101. Dissertation, Jiangnan University.

Xu Z, Liu W, Chen C-C, Li Q, Huang J-W, Ko T-P, Liu G, Liu W, Peng W, Cheng Y-S, Chen Y, Jin J, Li H, Zheng Y, Guo R-T (2016) Enhanced a-zearalenol hydrolyzing activity of a mycoestrogen-detoxifying lactonase by structurebased engineering. ACS Catal 6(11):7657-7663. https://doi.org/10.1021/ acscatal.6b01826

Yin Q (2018) A formulation for the simultaneous degradation of aflatoxin and zearalenone. China Patent 108034598 A, May 2018.

Zhang X (2010) Production, purification and application of ligninolytic enzymes from Phanerochaete chrysosporium. Dissertation, Zhejiang University of Technology.

Zhang Y, Wang P, Kong Q, Cotty PJ (2021) Biotransformation of aflatoxin B by Lactobacillus helviticus FAM22155 in wheat bran by solid-state fermentation. Food Chem. https://doi.org/10.1016/j.foodchem.2020.128180

Zhang Z, Xu W, Wu H, Zhang W, Mu W (2020) Identification of a potent enzyme for the detoxification of zearalenone. J Agric Food Chem 68(1):376-383. https://doi.org/10.1021/acs.jafc.9b06223

Zhou C (2017) Morphological and molecular identification of Gliocladium roseum. Shandong Forestry Sci Technol 4:61-62. https://doi.org/10.3969/j. issn.1002-2724.2017.04.017

Zhou Y, Wu S, Wang F, Li Q, He C, Duan N, Wang Z (2020) Assessing the toxicity in vitro of degradation products from deoxynivalenol photocatalytic degradation by using upconversion nanoparticles@TiO, composite. Chemosphere. https://doi.org/10.1016/j.chemosphere.2019.124648

\section{Publisher's Note}

Springer Nature remains neutral with regard to jurisdictional claims in published maps and institutional affiliations. 